\title{
Repetitive speech phenomena in Parkinson's disease
}

\author{
Th Benke, C Hohenstein, W Poewe, B Butterworth
}

\begin{abstract}
Objectives-Repetitive speech phenomena are morphologically heterogeneous iterations of speech which have been described in several neurological disorders such as vascular dementia, progressive supranuclear palsy, Wilson's disease, and Parkinson's disease, and which are presently only poorly understood. The present, prospective study investigated repetitive speech phenomena in Parkinson's disease to describe their morphology, assess their prevalence, and to establish their relation with neuropsychological and clinical background data.

Methods-Twenty four patients with advanced Parkinson's disease and 29 subjects with mid-stage, stable idiopathic disease were screened for appearance, forms, and frequency of repetitive speech phenomena, and underwent a neuropsychological screening procedure comprising tests of general mental functioning, divergent thinking and memory. Patients with advanced Parkinson's disease had a significantly higher disease impairment, longer disease duration, and an unstable motor response to levodopa with frequent on-off fluctuations. Both groups were well matched as to their demographical, clinical, and cognitive background. Perceptual speech evaluation was used to count and differentiate forms of repetitive speech phenomena in different speech tasks. To compare the effect of the motor state, the appearance of repetitive speech phenomena was also assessed in a subgroup of patients with advanced Parkinson's disease during the on versus the off state.
\end{abstract}

Results-Speech repetitions emerged mainly in two variants, one hyperfluent, formally resembling palilalia, and one dysfluent, stuttering-like. Both forms were present in each patient producing repetitive speech phenomena. The repetitive speech phenomena appeared in 15 patients $(28.3 \%), 13$ of whom belonged to the advanced disease group, indicating a significant preponderance of repetitive speech phenomena in patients with a long term, fluctuating disease course. Repetitive speech phenomena appeared with almost equal frequency during the on and the off state of patients with advanced Parkinson's disease. Their distribution among different variants of speech was disproportional, with effort demanding speech tasks producing a significantly higher number of repetitive speech phenomena over semiautomatic forms of speech.

Conclusions-In idiopathic Parkinson's disease repetitive speech phenomena seem to emerge predominantly in a subgroup of patients with advanced disease impairment; manifest dementia is not a necessary prerequisite. They seem to represent a deficit of motor speech control; however, linguistic factors may also contribute to their generation. It is suggested that repetitions of speech in Parkinson's disease represent a distinctive speech disorder, which is caused by changes related to the progression of Parkinson's disease. (F Neurol Neurosurg Psychiatry 2000;69:319-325)

Keywords: Parkinson's disease; repetitive speech phenomena

Patients with Parkinson's disease often present with a complex impairment of speech, commonly recognised as dysarthrophonia. ${ }^{1-6}$ It is generally accepted that parkinsonian dysarthria emerges due to neurogenic impairments at the respiratory, phonatory, and articulatory level. Based on an earlier proposition by Leyser, ${ }^{7}$ Critchley $^{8}$ has classified the speech disorders of patients with Parkinson's disease into akinetic, rigid, hyperkinetic, and iterative (or repetitive) forms of dysarthrophonia. This symptomatic classification suggests that the two main elements of Parkinson's disease, bradykinesia and rigidity, exert an influence on the motor speech system. The equivalents of hypokinesia or rigidity have been described as monopitch, reduced stress, imprecisely produced consonants, breathless voice, and monoloudness. ${ }^{1-356}$ Hyperkinesia has been hypothesised to cause speech impairments such as voice harshness, excess loudness variations, imprecise articulation, and disintegration of respiratory processes. ${ }^{9}$ Iterative or repetitive speech phenomena are the least studied features of the articulatory disorder in Parkinson's disease. Repetitive speech phenomena may be characterised broadly as a group of variable speech iterations with immediately successive repetitions of syllables, words, or phrases. Due to their heterogeneity, they have been labelled differently, as stuttering, ${ }^{10}$ speech iterations, ${ }^{11}$ or palilalia. ${ }^{13}{ }^{13}$ With the exception of palilalia, which is a frequent sequel of postencephalitic Parkinson's disease ${ }^{7}{ }^{74} 15$ the phenomena are considered rare symptoms of idiopathic Parkinson's disease. ${ }^{4}$ However, only few studies have undertaken a detailed search for repetitive speech phenomena in Parkinson's 
disease. Koller $^{10}$ studied six patients with parkinsonian symptoms who developed dysfluent, stuttering-like repetitions which were most pronounced in self formulated speech, affected initial phonemes more often, and were not alleviated by levodopa therapy. Hertrich $e t$ al ${ }^{11}$ described repetitive speech phenomena in a cognitively declined patient with Parkinson's disease appearing as predominantly monosyllabic iterations occurring at all word positions. Ackermann et $a l^{4}$ noted a patient with idiopathic, late stage Parkinson's disease with on-off fluctuations who developed palilalia during peak dose hyperkinesia, pointing to a possible relation between the appearance of repetitive speech phenomena and the drug induced on phase in long term Parkinson's disease. These studies have called attention to the existence of repetitive speech phenomena in Parkinson's disease and to possible influential variables such as stage of disease, effect of levodopa treatment, and cognitive background. However, due to the lack of data which have been derived systematically from a larger patient population, the role of speech iterations in Parkinson's disease remains unclear. The present study was undertaken to describe the characteristics of repetitive speech phenomena in idiopathic Parkinson's disease. More specifically, the aim was to describe the morphology of verbal iterations, to establish their prevalence in different forms of the disease, and to evaluate their relation to neuropsychological and clinical background data.

\section{Patients and methods}

PATIENTS

Fifty three patients with Parkinson's disease were investigated in a prospective study encompassing clinical, speech, and neuropsychological tasks. All patients were diagnosed according to UK Parkinson's Disease Society Brain Bank criteria. ${ }^{16}$ All patients had two of the three cardinal signs (bradykinesia, rigidity, tremor) and showed no evidence of secondary parkinsonism due to antidopaminergic medication, or clinically relevant cerebrovascular disease. Additional criteria were the absence of dementia, major depression, aphasia, previous alcohol or drug misuse, brain trauma, or severe hearing loss. Subjects were inpatients and outpatients of the Clinic of Neurology, Innsbruck who gave their verbal informed consent to participate in the study. Patients were divided into groups according to the stability of their drug response. Twenty nine patients who had a stable response to levodopa were compared with 24 patients who had reached a more advanced disease stage with unstable drug response, including frequent motor fluctuations, unpredictable wearing off phenomena, and dyskinesia. Degree of overall impairment due to Parkinson's disease was rated during on states on the Hoehn and Yahr scale. A neuropsychological screening procedure was performed to exclude demented patients and to compare both patient groups for their basic cognitive abilities. The test battery included the mini mental state examination (tapping orientation, speech, attention, memory, and constructional abilities ${ }^{17}$ ); a multiple choice vocabulary test for the estimation of premorbid intelligence ${ }^{18}$; and two semantic word list generation tasks (number of generated animal names and supermarket items during a period of 60 seconds; perseverative responses were subtracted from the total count). Short and long term retention of verbal material was assessed using the story recall section of the Rivermead behavioural memory test. $^{19}$ In all patients, motor ratings, speech tasks, and neurobehavioural background tests were administered in the morning during the on state about 1 hour after drug administration.

\section{PERCEPTUAL SPEECH EVALUATION}

It was the aim of this speech assessment to detect subjects with repetitive speech phenomena, to evoke speech in different categories of natural language, and to characterise and count their repetitions on the basis of perceptual measurement. During the test procedure patients were seated in a quiet room. All patients received detailed instructions on how to perform each test and were asked to speak as slowly and distinctively as possible. Five speech production tasks were tested. Patients were asked to produce spontaneous speech during an extensive, semistructured interview with questions regarding details of their disease, profession, family, and place of growing up. Naming was evoked by having patients describe the details of a complex scenic picture containing common objects. A reading test required reading aloud two short paragraphs of a prose text, both presented in large print on an A4 sized sheet of paper; one paragraph contained normal words, whereas in the second passage $15 \%$ of all words had been changed to phonologically regular non-words. Similarly, repetition of speech was tested using 15 words and four sentences, both of increasing length, taken from the Aachener Aphasietest, ${ }^{20}$ and a corresponding section using non-words and sentences containing neologisms. Automatic speech was assessed by asking patients to name the months of the year. Spontaneous speech, naming, reading, and repetition of text containing neologisms were considered forms of effortful speech production compared with automatic speech, reading, and repetition of normal text which were judged semiautomatic speech production. To establish the effect of on and off states on the appearance of repetitive speech phenomena, seven patients of the advanced Parkinson's disease group who had marked motor fluctuations were tested twice, once during the on and once in an off phase using parallel but equivalent test materials for the assessment of each speech modality.

Considerable overlaps exist between the labelling of various forms of repetitive verbal behaviour such as iterations, perseverations, palilalia, acquired neurogenic stuttering, ${ }^{21}$ recurring utterances, and stereotypies (for definitions and a review of repetitive verbal behaviour see Wallesch ${ }^{22}$ ). For the purpose of this study, the definition of repetitive speech 
Table 1 Demographics, clinical characteristics, and neuropsychological test results

\begin{tabular}{llll}
\hline & $a P D(n=24)$ & $s P D(n=29)$ & $p$ Value \\
\hline Age (y) & $65(41-78)$ & $70(45-84)$ & NS \\
Years of education & $8(4-12)$ & $8(6-12)$ & NS \\
$\begin{array}{l}\text { Duration of disease (years) } \\
\text { Hoehn and Yahr stage }\end{array}$ & $11(3-18)$ & $5(2-17)$ & 0.00 \\
Side of predominant motor impairment & $3(1-5)$ & $3(1-3.5)$ & 0.01 \\
$\quad$ \% right:\% left) & $56.5: 43.5$ & $50: 50$ & NS \\
Sex distribution (\% female:male) & $25: 75$ & $38: 62$ & NS \\
MMSE & $26(15-30)$ & $28(21-30)$ & NS \\
Premorbid IQ & $100.5(69-136)$ & $100.5(85-134)$ & NS \\
RBMT, immediate & $7(1-22)$ & $7(1-14)$ & NS \\
RBMT, long & $5(0-18)$ & $6(0-11)$ & NS \\
WLG & $17.5(4-34)$ & $20.5(5-33)$ & NS
\end{tabular}

Values are medians (range); p values by Student's $t$ test for independent samples (demographics); $\chi^{2}$ analysis (sex and side distributions), and Mann-Whitney $U$ test (neuropsychological tasks); $\mathrm{aPD}=$ advanced Parkinson's disease with motor fluctuations; $\mathrm{PPD}=$ stable, non-fluctuating Parkinson's disease; $\mathrm{MMSE}=$ mini mental state examination; premorbid $\mathrm{IQ}=$ premorbid intelligence quotient; RBMT immediate $=$ score of immediate story recall of the Rivermead behavioural memory test; RBMT long=score of long delay story recall of the RBMT; WLG=sum of both word list generation tasks.

phenomena was acoustically identifiable iterations of phonemes, syllables, words, or utterances. They were categorised using four distinctive criteria: fluency (fluent $v$ nonfluent), speech rate (accelerando $v$ constant speech rate), articulation (intact $v$ poor articulation), and loudness (constant $v$ inconstant speech volume). Each patient was screened for the appearance of repetitive speech phenomena. The speech of patients with repetitive speech phenomena was recorded on audiotape or videotape and entirely transcribed and analysed word by word. Due to the limited distinguishing quality of a perceptual speech analysis, and the often reduced articulatory precision and low volume in Parkinsonian dysarthrophonia, it was often impossible to identify the number of iterated speech segments within a single repetitive speech phenomenon. Therefore, each phenomenon was counted as a single entity, irrespectively of the number of its repeated speech elements (syllables, words, utterances, etc). The number of phenomena across speech tasks were counted from the written speech protocol and expressed as percentage of the patient's total word sample.

\section{Results}

DEMOGRAPHIC, CLINICAL, AND

NEUROPSYCHOLOGICAL VARIABLES

As groups, patients with advanced Parkinson's disease or stable Parkinson's disease were similar in demographical variables, their general mental state, and performance on the verbal memory and the two semantic fluency tasks. In the advanced Parkinson's disease group, disease duration was significantly longer, and the amount of disease severity as measured by the Hoehn and Yahr scale was significantly greater. Mean scores on general mental functioning (MMSE) and memory were above the cut off for an impairment indicating dementia (table 1).

FORMS OF REPETITIVE SPEECH PHENOMENA IN PARKINSON'S DISEASE

An analysis and comparison of the transcribed iterations indicated that they could be grouped in two types. repetitive speech phenomena type 1 , formally resembling palilalia ${ }^{14}{ }^{23}$ were hyperfluent repetitions uttered fast and with increasing speech rate; due to their often poor articulation and decreasing loudness they became increasingly blurred or murmured. By contrast, repetitive speech phenomena type 2 were dysfluent, prolonged, stuttering-like iterations which were relatively well articulated at a constant rate and loudness. As both types of speech repetitions were so phenomenologically distinct, it was thought that there was no need to establish interrater reliabilities. A small percentage of repetitive speech phenomena did not fit into one of both categories or was impossible to differentiate according to the above described criteria (type 3). Example utterances of the two most common types are summarised in table 2 .

PREVALENCE OF REPETITIVE SPEECH PHENOMENA IN PARKINSON'S DISEASE

From a total of 53 patients with Parkinson's disease, $15(28.3 \%)$ displayed repetitive speech phenomena. Of those, 13 belonged to the advanced Parkinson's disease and two to the stable Parkinson's disease sample. Thus, the prevalence of repetitive speech phenomena in patients with advanced Parkinson's disease was $54.3 \%$, whereas in the stable Parkinson's disease sample it was only $6.9 \%$. This indicates a significant preponderance of repetitive speech phenomena in patients with long term disease and fluctuating motor response to levodopa ( $p=0.007$, Fisher's exact test). Within the advanced Parkinson's disease group, the 13 subjects producing repetitive speech phenomena did not differ from the rest in demographics, duration of disease, and motor or cognitive performance.

Table 2 Characteristics of two repetitive speech phenomena in Parkinson's disease

\begin{tabular}{|c|c|c|c|c|}
\hline & Fluency & Speech rate & Other speech characteristics & Example utterance \\
\hline Type 1 (hyperfluent) & Fluent rushes of speech & $\begin{array}{l}\text { Increasing (accelerando), } \\
\text { hastening }\end{array}$ & $\begin{array}{l}\text { Often poorly articulated, } \\
\text { occasionally decreasing } \\
\text { loudness (decrescendo) }\end{array}$ & $\begin{array}{l}\text { "meinmeinmeine parkinsonkrankheit" } \\
\text { "kraftfahrscheinzeugzeug" } \\
\text { "mitmitmit medikamenten begobegonnen" } \\
\text { "unddieunddie tiere" } \\
\text { "nichtnicht mehr agieren, nichtnichtnicht reagieren" } \\
\text { "an die tiere verffffverfüttert" } \\
\text { "ich bbbbin dann nach ... gegangen" }\end{array}$ \\
\hline Type 2 (dysfluent) & $\begin{array}{l}\text { Non-fluent, clonic, } \\
\text { stuttering-like, staccato, } \\
\text { short intervals between } \\
\text { iterated speech segments }\end{array}$ & Constant & $\begin{array}{l}\text { Well articulated, loudness } \\
\text { constant }\end{array}$ & $\begin{array}{l}\text { "von kopf bis fuß u-u-u-u-un-untersucht" } \\
\text { "hat schlecht a-a-a-a-an-angefangen" } \\
\text { "wir ar-wir-arbeiten viel" } \\
\text { "es war sein schwa-sein-schwager" } \\
\text { "ein auto-autoreifen" } \\
\text { "ohne tab-ohne-tabletten" }\end{array}$ \\
\hline
\end{tabular}




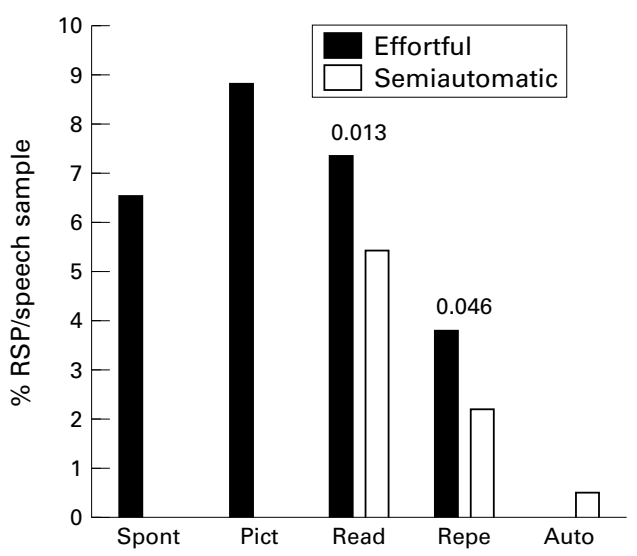

Percentage of repetitive speech phenomena as found in different categories of effortful and semiautomatic speech. Spont=spontaneous speech, Pict=naming in picture description task, Read=reading, Repe=repetition, Auto=automatic speech. $p$ Values refer to paired samples $t$ test.

\section{AMOUNT AND TYPES OF REPETITIVE SPEECH} PHENOMENA IN PARKINSON'S DISEASE

The total recorded speech sample of patients displaying repetitive speech phenomena was 8117 words; 470 repetitive speech phenomena were counted in this sample. The counts of repetitive speech phenomena types 1,2 , and 3 were 174,227 , and 69 , respectively. Thus, type 1 constituted $37 \%$, type $248.3 \%$, and type 3 only $14.7 \%$ of all iterations. Within the group of patients producing repetitive speech phenomena there was little variation of this distribution pattern. Each patient with repetitive speech phenomena produced all three types. The percentages of types 1,2 , and 3 were 2.14 $\%, 2.79 \%$, and $0.85 \%$ of the total word count. Patients with Parkinson's disease iterated phonemes, syllables, words, and utterances, but most often single syllables and words. The number of acoustically identifiable iterations ranged from one to six; most repetitive speech phenomena had two to three iterations. Type 1 and type 2 were most often located at word beginnings, but were also found amidst and at the end of words and phrases. Occasional blends of type 1 and type 2 were also found (for example, "ich habe eine schwe-eineine-schwester" "nachher wa-wa-war mein vater ver-ver-vermißt im krieg". The two patients with stable Parkinson's disease who iterated speech had a similar amount and proportion of repetitive speech phenomena types as found in patients with advanced Parkinson's disease.

Table 3 Comparison of RSP during on and off state in seven patients with advanced Parkinson's disease

\begin{tabular}{|c|c|c|c|c|c|c|}
\hline & \multicolumn{3}{|c|}{ On state } & \multicolumn{3}{|c|}{ Off state } \\
\hline \multicolumn{7}{|l|}{ Word count: } \\
\hline Sum & \multicolumn{3}{|l|}{4932} & \multicolumn{3}{|l|}{4615} \\
\hline Median & \multicolumn{3}{|l|}{687} & \multirow{2}{*}{\multicolumn{3}{|c|}{$\begin{array}{l}660 \\
470-1080\end{array}$}} \\
\hline \multirow[t]{2}{*}{ Range } & \multicolumn{3}{|c|}{$413-865$} & & & \\
\hline & $n R S P$ & $\% R S P$ & Prop RSP & $n R S P$ & $\% R S P$ & Prop RSP \\
\hline RSP Type 1 & 69 & 1.39 & $34 \%$ & 58 & 1.26 & $32.2 \%$ \\
\hline RSP Type 2 & 93 & 1.88 & $45.8 \%$ & 84 & 1.81 & $46.4 \%$ \\
\hline RSP Type 3 & 41 & 0.83 & $20.2 \%$ & 39 & 0.84 & $21.4 \%$ \\
\hline RSP Type $1+2+3$ & 203 & 4.10 & $100 \%$ & 181 & 3.89 & $100 \%$ \\
\hline
\end{tabular}

Word count=number of words recorded across all speech tasks. nRSP=absolute number of RSP $\% \mathrm{RSP}=$ percentage of RSP per total word count; Prop RSP=proportion of RSP per total number There were no significant differences of word or RSP counts between the two states (Mann-Whitney $U$ test).
DISTRIBUTION OF REPETITIVE SPEECH

PHENOMENA AMONG SPEECH TASKS

There was uneven distribution of repetitive speech phenomena among the tested speech tasks (figure). Contrary to a previous case description ${ }^{24}$ where repetitive speech phenomena were strictly linked to a task of speech repetition, in this study picture naming and spontaneous speech generated the highest percentage of repetitive speech phenomena, whereas semiautomatic speech yielded only one in the whole sample of repetitions. Furthermore, reading and repeating nonwords produced significantly more repetitive speech phenomena than reading and repeating normal text ( $\mathrm{p}=0.013$ and 0.046 , respectively). It also seems noteworthy that a relatively large number (18\%) of all repetitive speech phenomena were provoked by word finding difficulties during spontaneous speech or during confrontation naming in the picture description task. Only $8 \%$ of all situations with word finding difficulties were not coupled with repetitive speech phenomena.

REPETITIVE SPEECH PHENOMENA DURING THE ON VERSUS THE OFF STATE

To evaluate the effect of the on and off states on the appearance of repetitive speech phenomena, seven patients with advanced Parkinson's disease who agreed to participate in this study were assessed during both states. The order of examinations in the on and off state was counterbalanced in this subgroup. Parallel test materials were used in both states. Table 3 shows a direct comparison of the appearance of repetitive speech phenomena in both functional states. As evident from this table, the amount of words spoken in both states was about the same. There was a tendency for repetitive speech phenomena to appear more often in the on state. However, there was no significant difference between the number of repetitive speech phenomena in both states. Also, types 1, 2, and 3 had similar prevalences and a similar distribution pattern in both motor states. Similarly, a detailed comparison of individual speech tasks (spontaneous speech, naming, reading, repetition, and automatic speech) yielded no significant difference in individual numbers or profiles of produced repetitive speech phenomena in the on versus the off state. The only qualitative difference between both states were poorer articulation and decreased volume of repetitive speech phenomena in the off state in general.

\section{Discussion}

Since Pick's ${ }^{12}$ and Merzbach's ${ }^{25}$ original observations in patients with vascular lesions, it is well recognised that lesions of the basal ganglia may be associated with repetitive speech phenomena. Later descriptions have focused on the appearance of stuttering in Parkinson's disease, ${ }^{7810111424}$ progressive supranuclear palsy, ${ }^{26}{ }^{27}$ Tourette's syndrome, ${ }^{28}$ or in Wilson's disease. In an attempt to learn more about repetitive speech behaviour in Parkinson's disease, we have analysed repetitive speech phenomena in a cohort of carefully selected, 
non-demented patients with idiopathic Parkinson's disease. The principal findings show that there are two clearly discernible forms of the phenomena in Parkinson's disease; that repetitions of speech are almost exclusively present in a subgroup of patients with Parkinson's disease with advanced disease stage and unstable motor response; furthermore, that repetitive speech phenomena appear both in the on and the off state; and finally that they are not necessarily coupled with dementia.

With the exception of two patients with stable Parkinson's disease, repetitive speech phenomena in this study were only found in patients with advanced, long term Parkinson's disease. In this subgroup, about half of all patients produced speech iterations. Even if the chosen selection criteria do not allow us to establish their general prevalence, the numbers of iterations found disproves the notion that repetitive speech phenomena are rare in Parkinson's disease, ${ }^{429}$ as in our study they appeared in $28 \%$ of the total Parkinson's disease sample, and the amount of iterated speech was almost $6 \%$ of the elicited total word count. Despite this strong association with unstable, fluctuating Parkinson's disease, it seems notable that iterations in patients with advanced Parkinson's disease were generated both during the on and the off state. Furthermore, they emerged in both motor states with similar forms and distribution patterns among speech tasks. These findings do not support previous assumptions that repetitive speech phenomena can be explained as symptoms of levodopa induced hyperkinesia. ${ }^{24} 29$ However, in the light of the small sample size the results of this study must be interpreted with caution and will need further, more detailed replication. The coupling between repetitive speech phenomena and advanced Parkinson's disease suggests that the events during the progression of the disease-namely, neuron degeneration and transmitter disturbances ${ }^{30}$ may also be the pathophysiological mechanisms responsible for the generation of the speech iterations.

As it is well known that repetitive speech phenomena appear in patients with dementia, ${ }^{15} 2429^{31-33}$ we were particularly interested in investigating the cognitive status of our patients with Parkinson's disease and repetitive verbal behaviour. Impairments of orientation, memory, and verbal associative functions are among the most prominent findings of a developing dementia in patients with Parkinson's disease. ${ }^{34-36}$ In the present study, neuropsychological background tests of patients with stable Parkinson's disease or advanced Parkinson's disease showed normal and equivalent group means on tasks tapping general mental abilities and verbal memory; scores on a word list generation task were in the lower normal range. It can therefore be assumed that repetitive speech phenomena may also be found in association with an average cognitive status as assessed by standard tests of memory and orientation, and that dementia may not be a prerequisite for the iterations

Based on the morphological characteristic of repetitive speech phenomena, simple rating categories of speech such as fluency, rate, articulation, and loudness were used to obtain a classification of the phenomena. With the exception of amorphous (type 3) speech repetitions, which accounted only for a minor percentage of speech iterations, two main patterns could be differentiated (table 1). Type 1 comprised hyperfluent, poorly articulated iterations, mostly uttered with increasing speech rate and decreasing loudness, closely resembling the classic description of palilalia. $^{8}{ }^{14}$ 37-38 These iterations have previously been described in postencephalitic parkinsonism, ${ }^{15}{ }^{39}$ as well as in many neuropsychiatric disorders. ${ }^{242528} 293233384041$ Type 2 was a non-fluent, well articulated iteration, pronounced with constant loudness and rate. This was produced in a staccato-like manner and resembled earlier descriptions of stuttering in Parkinson's disease. ${ }^{1011}$ Similar to an earlier report, ${ }^{11}$ iterations occurred at all word positions. In this study, the two main types of repetitive speech phenomena, type 1 and type 2 , constituted $37 \%$ and $48.3 \%$ of all iterations, respectively; thus the proportion was roughly $1: 1.3$. This distribution remained largely constant among different speech tasks. Both types appeared in each patient producing speech iterations. Occasional blends of type 1 and type 2 were also found. With the reservation that a purely perceptual analysis of parkinsonian dysarthrophonia can only provide a quantitative estimation of these variables, both repetitive speech phenomena types did not differ in the iterated speech material - that is, their number of iterations, the speech segment being iterated (syllable, word, or sentence), as well as the locus of reiteration within utterances (begin, medial, end). Thus, both types of repetitive speech phenomena differ in their acoustic properties such as fluency, rate, loudness or articulatory control, but not remarkably for the iterated speech substrate, such as the number of repeated elements, the task, or the reiteration type (syllable, word, or utterance). Also, each type was present in each patient, indicating that the disease may bring forth two, or possibly even several different forms of repetitive speech, without creating subgroups of specificity among patients. These findings confirm the coexistence of hyperfluency and dysfluency in one disease, as well as the variability of speech rate, articulatory clearness, and loudness. They are in line with other findings pointing to the variability of some speech variables in Parkinson's disease, ${ }^{468}$ which may appear as a continuum of symptoms rather than a uniform profile of speech.

At present, the origin of repetitive speech phenomena in Parkinson's disease is unclear. As the results of this study are based on a purely perceptual analysis of parkinsonian speech and lack other, more objective-for example, kinematic observations - they can only bring forward two hypotheses regarding generation of the iterations. The motor hypothesis holds that repetitive speech phenomena are the result of a malfunction at the level of motor speech, probably resulting from a disintegration of subcorticocortical interplay, whereby 
the basal ganglia stimulate speech activity in the cortex in an uncontrolled manner ${ }^{29}$; alternatively, defective execution of preprogrammed motor sequences may result in an impairment of the duration and fluency of speech events. ${ }^{42-46}$ More specifically, repetitive speech phenomena may be speech equivalents of the "freezing" or "motor block" phenomenon, a sudden and short lasting break in motion as well as inhibition in executing a movement, or in switching from one movement pattern to another. ${ }^{46}{ }^{47}$ Motor blocks are often found in advanced Parkinson's disease, occur independently of the timing of levodopa dosage, may appear in both the on and off phase, and affect gait, finger movements, and speech. During freezing episodes of finger tapping an excessive increase of frequency combined with a reduction of movement amplitude has been found, ${ }^{48}$ features which bear some morphological similarity with the accelerando and decrescendo of the hyperfluent repetitive speech phenomena found in this speech study. Similarly, an increase in articulatory repetition rate with a concomitant reduction of movement amplitude has recently been demonstrated by means of electromagnetic articulography in a patient with Parkinson's disease with speech freezing. ${ }^{49}$ Finally, motor speech can also be paced by released tremor oscillations, a "hastening" phenomenon found in a subgroup of patients with Parkinson's disease during various motor tasks. ${ }^{49}{ }^{50}$ Freezing was present in several patients of this study; however, as the primary aim was the investigation of repetitive speech phenomena, no detailed assessment was performed as to the prevalence of blocking phenomena and their possible correlation with iterations of speech.

The complementary, cognitive hypothesis claims that repetitive speech phenomena are the result of an impairment at the linguistic, prearticulatory level, particularly by a deficit of mechanisms which are responsible for the generation of the phonetic plan. ${ }^{52}$ This plan contains all the information about the word form and the serial organisation of speech elements, Alternatively, there may be a defective interplay between the phonetic plan and the motor speech assembly. Some findings from this study suggest that repetitive speech phenomena in Parkinson's disease may have a cognitive component. It is evident that the phenomena appear significantly more often in effortful than in semiautomatic speech (figure). Furthermore, the frequent $(92 \%)$ coupling of iterations with word finding difficulties may be taken as a hint that an impairment at the prearticulatory level has an effect on motor speech. In a case study of two demented patients producing monosyllabic iterations ${ }^{33}$ the view has been taken that repetitive speech phenomena linked to word finding difficulties may function as fillers which are produced during the generation of relatively inaccessible content words. Further support of the "cognitive" hypothesis also comes from a recent study which has found that parkinsonian dysarthria may also be influenced by linguistic demands. ${ }^{5}$ According to this concept, the repetitive forms of dysarthropho- nia in Parkinson's disease ${ }^{8}$ may be both a disorder of speech and of language.

We are grateful for the comments and suggestions of Hermann Ackermann and two anonymous reviewers who provided helpful insights for the preparation of this paper. Parts of this paper were presented as a poster at the 9th TENNET Conference, Montreal, 1998

1 Darley FL, Aronson AE, Brown JR. Differential diagnostic patterns of dysarthria. $\mathcal{F}$ Speech Hear Res 1969;12:246-69. 2 Darley FL, Aronson AE, Brown JR. Clusters of deviant speech dimensions in the dysarthrias. I Speech Hear Res 1969;12:462-96.

3 Kent RD, Rosenbek JC. Prosodic disturbance and neurologic lesion. Brain Lang 1982;15:259-91.

4 Ackermann H, Ziegler W. Die Dysarthrophonie des Parkinsonsyndroms. Fortschr Neurol Psychiatr 1989;57:149-60.

5 Ackermann H, Ziegler W. Articulatory deficits in Parkinsonian dysarthria: an acoustic analysis. 7 Neurol Neurosurg Psychiatry 1991;54:1093-8.

6 Mlcoch GA. Diagnosis and treatment of parkinsonian dysarthria. In: Koller WC, ed. Handbook of Parkinson's disease, 2nd ed. New York: Dekker, 1992.

7 Leyser E. Die zentralen Dysarthrien und ihre Pathogenese. Klinische Wochenschrift 1923;2:2176-9.

8 Critchley EMR. Speech disorders of Parkinsonism: a review. Critchley EMR. Speech disorders of Parkinson
f Neurol Neurosurg Psychiatry 1981;44:751-8.

f Neurol Neurosurg Psychiatry 1981;44:751-8.
Darley FL, Aronson AE, Brown JR. Motor speech disorders. Philadelphia: Saunders, 1975.

10 Koller WC. Dysfluency (stuttering) in extrapyramidal disease. Arch Neurol 1983;40:175-7.

1 Hertrich I, Ackermann H, Ziegler W, et al. Speech iterations in Parkinsonism. Aphasiology 1993;7:395-406.

12 Pick A. Die Palilalie, ein Teilstück striärer Motilitätsstörung. In: Pick A, ed. Die neurologische Forschungsrichtung in der Psychopathologie und andere Aufsätze. Abhandlungen aus der Neurologie, Psychiatrie, Psychologie und ihren Grenzgebieten. Berlin: Karger 1921;13:178-224.

13 Siegfried J. Die Parkinson'sche Krankheit und ihre Behandlung. Berlin: Springer, 1968.

14 Sterling W. Palilalie et le symptome linguosalivaire dans le Parkinsonisme encephalitique. Rev Neurol (Paris) 1924;1: 205-20.

15 Critchley M. On palilalia. Fournal of Neurology and Psychopathology 1927-8;18:23-31.

16 Gibb WR, Lees AJ. The relevance of the Lewy body to the pathogenesis of idiopathic Parkinson's disease. If Neurol Neurosurg Psychiatry 1988;51:745-52.

17 Folstein MF, Folstein SE, McHugh PR. Mini-mental state. f Psychiatr Res 1975;12:189-98.

8 Lehrl S. Mehrfachwahl-Wortschatz-Intelligenztest MWT-B, 2nd revised ed. Erlangen: Perimed, 1989

19 Wilson BA, Cockburn J, Baddeley A. The Rivermead behavioural memory test. Suffolk: Thames Valley Test, 1989.

20 Huber W, Poeck K, Weniger D, et al. Der Aachener Aphasietest. Göttingen: Hogrefe, 1983.

21 Helm AN, Russell BB, Benson DF. Acquired stuttering. Neurology 1978;28:1159-65.

22 Wallesch CW. Repetitive verbal behaviour: functional and neurological considerations. Aphasiology 1990;4:133-54.

23 Souques A. Palilalia. Rev Neurol (Paris) 1908;16:340-3.

23 Souques A. Palilalia. Rev Neurol (Paris) 1908;16:340-3. symptom of levodopa induced hyperkinesia in Parkinson's disease. $\mathcal{F}$ Neurol Neurosurg Psychiatry 1989;52:805-7.

25 Merzbach A. Die Sprachiterationen und ihre Lokalisation bei Herderkrankungen des Gehirns. Fournal für Psychologie und Neurologie 1928;36:211-316.

26 Lebrun Y, Devreux F, Rousseau J. Language and speech in a patient with a clinical diagnosis of progressive supranuclear palsy. Brain Lang 1986;27:247-56.

27 Kluin KJ, Foster NL, Berent S, et al. Perceptual analysis of speech disorders in progressive supranuclear palsy. Neurology 1993;43:563-6.

28 Shapiro AK, Shapiro ES, Bruun RD. Gilles-de la Tourette syndrome. New York: Raven Press, 1978.

29 Garcia C. Neuroleptisch bedingte Palilalie. Nervenarzt 1990;61:676-83.

30 Fabbrini G, Mouradian MM, Juncos LJ, et al. Motor fluctuations in Parkinson's disease: central pathophysifluctuations in Parkinson's disease: central pathophysi-
ological mechanisms, part 1. Ann Neurol 1988;24:366-71.

31 Tissot R, Constantinidis J, Richard J. Pick's disease. In: Vinken PJ, Bruyn GW, Klawans HL, eds. Handbook of cliniVinken PJ, Bruyn GW, Klawans HL, eds. Handbook of clini-
cal neurology. Vol 46. Amsterdam: Elsevier 1985:233-46. cal neurology. Vol 46. Amsterdam: Elsevier 1985:233-46.
32 Kleist K. Die psychomotorischen Störungen und ihr Kleist K. Die psychomotorischen Storungen und ihr
Verhältnis zu den Motilitätsstörungen bei Erkrankungen der Stammganglien. Monatsschrift für Psychiatrie und Neurologie 1922;52:253-302

33 Benke T, Butterworth B. Palilalia: two case reports and several implications. Brain Lang 1994;47:368-70.

34 Levin BE, Katzen HL. Early cognitive changes and nondementing behavioral abnormalities in Parkinson's disease. In: WJ Weiner, AE Lang, eds. Advances in neurology. Vol 65, Behavioral neurology of movement disorders. New York:
Raven Press 1995 .

Jacobs DM, Marder K, Cote LJ, et al. Neuropsychological characteristics of preclinical dementia in Parkinson's disease. Neurology 1995;45:1691-6.

36 Benke T, Andree B, Hittmair M, et al. Sprachveränderungen Benke T, Andree B, Hittmair M, et al. Sprachveränderungen
bei der Demenz. Fortschr Neurol Psychiatr 1990;58:215-23. 37 Boller F, Albert M, Denes F. Palilalia. British fournal of Disorders of Communication 1975;10:92-7. 
38 Lapointe LL, Horner J. Palilalia: a descriptive study of pathological reiterative utterances. Fournal of Speech and Hearing

39 Balint A, Julius D. Sprachiterationen und Psychose bei Encephalitis epidemica. Monatsschrift für Psychiatrie und Neurologie 1925;58:102-20.

40 Horner J, Massey EW. Progressive dysfluency associated with right hemisphere lesions. Brain Lang 1983;18:71-85. 41 Yasuda Y, Akiguchi I, Ino M, et al. Paramedian thalamic and midbrain infarcts associated with palilalia. $\mathcal{F}$ Neurol Neurosurg Psychiatry 1990;53:797-9.

42 Ludlow CL, Connor NP, Bassich CL. Speech timing in Parkinson's and Huntington's disease. Brain Lang 1987;32 195-214

43 Volkmann J, Hefter H, Lange HW, et al. Impairment of temporal organization of speech in basal ganglia disease. Brain Lang 1992;43:386-99.

44 Marsden CD. The mysterious motor function of the basal ganglia. Neurology 1982;32:514-39.

45 Goldberg G. Supplementary motor area structure and function: review and hypotheses. Behav Brain Sci 1985;8: function:
46 Giladi N, MacMahon D, Przedborski S, et al. Motor blocks in Parkinson's disease. Neurology 1992;42:333-9.

47 Fahn S. The freezing phenomenon in parkinsonism. In: Fahn S, Hallett M, Lüders HO, et al, eds. Negative motor phenomena. Philadelphia: Lippincott-Raven, 1995.

48 Narabayashi H, Imai H, Yokochi $M$, et al. Case of pure akinesia without rigidity and tremor and with no effect by l-dopa. In: W Birkmayer, O Hornykiewicz, eds. Advances in Parkinsonism. Basel: Editiones Roche, 1976:335-42.

49 Ackermann $\mathrm{H}$, Gröne BF, Hoch G, et al. Speech freezing in Parkinson's disease: a kinematic analysis of orofacial movements by means of electromagnetic articulography. Folia Phoniatr 1993;45:84-9.

50 Logigian E, Hefter H, Rewiners K, et al. Does tremor pace repetitive voluntary motor behavior in Parkinson's disease. Arch Neurol 1991;30:172-9.

51 Levelt WJM. Speaking: from intention to articulation. Cambridge: MIT Press, 1989.

52 Butterworth B. Some constraints on models of language production. In: Butterworth B, ed. Language production. Vol 1: Speech and talk. London, Academic Press 1980,423-59.

\section{Call for Papers}

6th European Forum on Quality Improvement in Health Care

Thursday 29-Saturday 31 March 2001, Bologna, Italy

For full information contact: BMA/BMJ Conference Unit, BMA House, Tavistock Square, London, WC1H 9JP, UK tel: +44 (0) 2073836409 Fax: +44 (0) 2073836869 Email quality@bma.org.uk Or go to the website for full details: www.quality.bmjpg.com 